\title{
DEVELOPMENT OF A FRAMEWORK FOR IMPLEMENTING 3D SPATIAL DATA INFRASTRUCTURE IN OMAN - ISSUES AND CHALLENGES
}

\author{
K. Al Kalbani ${ }^{1}$, A. Abdul Rahman ${ }^{1}$, T. Al Awadhi ${ }^{2}$, F. Al shannaq ${ }^{3}$ \\ ${ }^{1}$ 3D GIS Research Lab, Faculty of Built Environment and Surveying, Universiti Teknologi, Malaysia, 81310 UTM Skudai, Johor \\ Bahru, Malaysia- kulaib2020@gmail.com; alias@utm.my \\ ${ }^{2}$ Department of Geography, College of Arts and Social Sciences, Sultan Qaboos University, Muscat, Oman-alawadhi@squ.edu.om \\ ${ }^{3}$ Jal Technology, Muscat, Oman-info@geojal.com.om
}

KEY WORDS: 2D and 3D Geospatial datasets, 2D SDI, 3D SDI

\begin{abstract}
The paper reviews that there are several issues and challenges in order to implement full 2D and 3D Spatial Data Infrastructure (SDI) in Oman. The state of current 2D SDI and 3D geospatial data has been investigated. Currently, Oman has made noticeable progress in 2D SDI but not yet in 3D domain. To date, there are no serious efforts and initiatives by the authority to materialize the 3D SDI. This paper ends by describing a framework for implementing the 3D SDI. We expect, these issues and challenges of 3D SDI in Oman can prompt better services for several potential users.
\end{abstract}

\section{INTRODUCTION}

Currently, the 3D (three-dimensional) geospatial tool and their related applications are considered as a trend in (GIS) for representing the reality in interactive $3 \mathrm{D}$ virtual environment. 3D is simply defined as "a representation of a threedimensional, real-world object in a map or a scene, with elevation values (z-values) which is stored within the feature's geometry" (ESRI, 2017). Therefore, the 3D technology has been widely deployed in all geo-related fields, such as photogrammetric surveying, cartography, civil engineering, planning and others. The capability of 3D technology now has attracted many specialists and researchers from different disciplines.

Most countries around the world have succeeded in applying 2D Spatial Data Infrastructure (SDI) for planning and infrastructure management (Ho et al., 2013; Alwardi, 2015). Other countries such as the United States of America (USA), Canada, some European countries, Asia and Australia are working toward 3D geospatial data infrastructure (SDI).

Nowadays, infrastructure in mega cities and urban areas are complicated in structure such as multi-floor buildings and underground infrastructures, require to use 3D geo-datasets. Thus, it is clear that the $2 \mathrm{D}$ geo-datasets are not able to accommodate complex 3D elements and structures. Additionally, employing the 2D GIS may not be a useful tool to analyze complex problems (Figure 1) and so there is an urgent need to shift to 3D GIS (Roić, 2012; Kitsakis et al., 2016). This means that efforts should be exerted to further study the possible functions of 3D SDI and its usefulness.

This paper is divided into four sections. The second section discusses the current status of 2D SDI in Oman including GIS history in Oman, Oman National Spatial Data Infrastructure (ONSDI) and some arising issues on the current implementations. Then, section three investigates the current status of 3D geospatial data in Oman and the limitation of 3D geospatial data in key sectors. Initial findings of the study are highlighted in section four by proposing a framework of Oman's national 3D SDI.

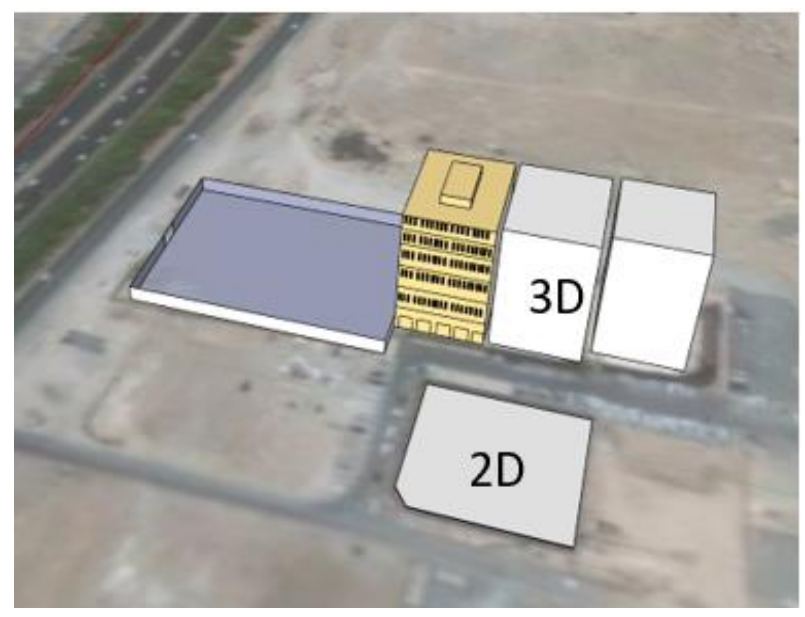

Figure 1.2D and 3D structures

\section{CURRENT STATUS OF 2D SDI IN OMAN}

Oman has been working with geo-datasets and information since more than 34 years ago. However, majority of the GIS databases are distributed at different authorities and GIS sectors around the country (Alwardi, 2015). However, most of these authorities produce their own geo-datasets based on their own requirements. In fact, the GIS authorities are using 2D geodatasets in their core businesses for mapping purposes.

\subsection{History of geospatial data in Oman}

In 1984, Oman government established the National Survey Authority (NSA) under the military supervision for surveying and mapping (for defense and civilian purposes).

Later, NSA created a geoinformation sector to collect spatial data and classify aerial photography and storage in geodatabase. NSA has formulated the Oman 2D geospatial manual (policies and standards) to be used as a reference by all users and stakeholders for data collection, maintenance, and dissemination of geospatial data to facilitate the production of harmonized geospatial data (Das et al., 2017). 
The first utilization of geoinformation in Oman for civil purposes was in 1989, through the Development Council which used the GIS for land information system (LIS entities). Later on, in 1992, the government established the first independent GIS department at Supreme Committee for town planning and censuses using the latest geoinformation platform (NCSI, 2017a).

Since then, geospatial culture was spread to many ministries among Oman to meet their own business requirements such as spatial data production, support the development and the urbanization plans.

The majority of these departments have started working separately based on their core businesses and they have established their own geodatabases with various standards and platforms (AutoCAD, MicroStation, ArcGIS). Through implementation of joint ventures between different ministries in Oman, has created a lot of challenges such as absence of unified geo-database, data error (codes, projections, indexes, metadata), lack of sharing, time consuming and budget wastage.

However, to address the challenges and issues that are related to geo-dataset, the government has established the Oman National spatial strategy (ONSS) and Oman National Spatial Data Infrastructure (ONSDI) strategy in 2014.

This was under the Supervision of Supreme Council for planning (SCP), the Steering Committee (SC), Directorate General of National Spatial Data Infrastructure and the National Centre for Statistics Information (NCSI) to coordinate, facilitate and support sharing and utilization of geospatial information across multiple government organizations in Sultanate of Oman (NCSI, 2017a).

Currently, there are two important geospatial agencies in Oman. They are the NCSI and NSA which emphasizes on the importance of the ONSDI as a tool for the government to implement geospatial in various sectors.

\subsection{ONSDI strategy}

The Steering Committee (SC), the National Centre for Statistics Information (NCSI) and Directorate General of National Spatial Data Infrastructure are working together to establish the union ONSDI which will be the platform to develop the National Geospatial Database (NGDB) (NCSI, 2017a).

In addition, the NGDB is being built based on the international standards (OGC/ISO) adopted for the Omani requirement. However, the ONSDI became the responsible for maintaining an efficient centralized platform for geospatial data. Moreover, ONSDI cooperates with Information Technology Authority (ITA) and NSA to enhance the GIS investment and avoids duplication of cost and centralized licenses.

The NGDB initiative has been completed 4 years from the date of existence. During that period, some aspects of its strengths have emerged as well as weaknesses as mentioned below:

a)

\section{Strengths}

- Centralized geospatial data in one portal.

- More flexible as geospatial data provider than other GIS agencies (public and private) in Oman.

- Minimize data production time (from 6 to 2 months).
- $\quad$ High quality and more accurate data.

\section{b) Weaknesses}

- Disconnected geospatial data provider with stakeholders' requirements.

- $\quad$ Lack of cooperation and coordination between public and private sectors and absence of unified standards.

\section{CURRENT STATUS OF 3D GEOSPATIAL DATA IN OMAN}

Oman has made noticeable progress in integrating the $2 \mathrm{D}$ geodataset into most of its governance infrastructure (NCSI, 2017a, 2017b). In contrast, the 3D geospatial implementation is limited and most of 3D data comes from AutoCAD, photogrammetric and LiDAR. Hence, most 3D GIS works have only been carried out in the academic researches as well as the consultative studies which are compulsory in any government project contract.

Moreover, up to now, there is no serious implementation for 3D geo-dataset in Oman sectors both in public and private.

\subsection{Limitation in 3D geospatial data Implementation in key Sectors of Oman}

As reported by NCSI, (2017a, 2017b) most of the Omani government sectors keep the flow of geospatial work in their GIS departments in 2D geospatial data, because they believed that the 2D geospatial data is good enough for their core business and fulfill their needs on regular basis. On the other hand, there is no legislation pushing the GIS authorities to utilize 3D geospatial data.

What is crucial is that though Oman National Spatial Data Infrastructure (ONSDI) and other geospatial sectors have stated their visions, objectives and standards about GIS, the actual 3D implementation seems to be uncertain. It can be said that the knowledge of the potential benefits of the $3 \mathrm{D}$ geospatial data is insufficient in the GIS domain through the implementation of it is still in the early stages.

\subsection{Need for 3D geospatial data in Oman}

The 3D SDI becomes one of the solutions for planning and managing many smart cities, thus, the $3 \mathrm{D}$ data is greatly required for urban, utilities, security, public safety and municipal entities (Li et al., 2013; Mao, 2014; Salim, 2017). In contrast, there are still some countries, of which Oman is not an exception, that rely entirely on processing their geospatial data in $2 \mathrm{D}$.

However, 3D SDI has a wide range of benefits. Implementation of $3 \mathrm{D}$ geospatial data can reduce costs and save time, increase accuracy and improve efficiency. It can also improve workflows, increase productivity, manage resources, enhance the quality of services, support decision making and offer further functionality through the z-dimension.

\subsection{D geospatial implementation and 3D SDI challenges}

In fact, most 3D SDI projects around the world even in the developed countries face a lot of challenges that affect the SDI upgrading process and sometimes it stops at various stages. Therefore, some of these projects (SDI) may need a constructive framework with expensive and multi-period budget. Moreover, 
they require a flexible platform to storage the data in various 3D formats.

In this point, Alsultan and Rahman (2015) and Alwardi (2015) mentioned that there are many issues facing the 2D SDI in their country (Saudi Arabia and Oman) which are financial wastage, lack of geospatial awareness, economic development challenge, lack of infrastructure and clarity with regards to geospatial strategy.

They also mentioned lack of trained human resources, data availability, cost of data acquisition, data completeness, budget constraints, lack of awareness in top management, data quality, data format compatibility, high hardware and software cost, rapid innovations in technology, unclear project scope and volume of data.

In fact, the most challenges and issues facing the implementation of 3D SDI are the same as for the 2D SDI. However, there are other obstacles can be encountered in relation to the 3D geo-dataset such as $3 \mathrm{D}$ complexity format, 3D legation and policy, 3D registration for objects, 3D data management, modeling and presenting information.

\section{FRAMEWORK FOR IMPLEMENTING 3D SDI IN OMAN}

3D SDI differs from one country to another in terms of different issues including the economy, 3D awareness, technology, framework and others (Kitsakis et al., 2016).

In fact, the full 3D SDI transformation needs a systematic framework for upgrading and integrating the $2 \mathrm{D}$ to $3 \mathrm{D}$

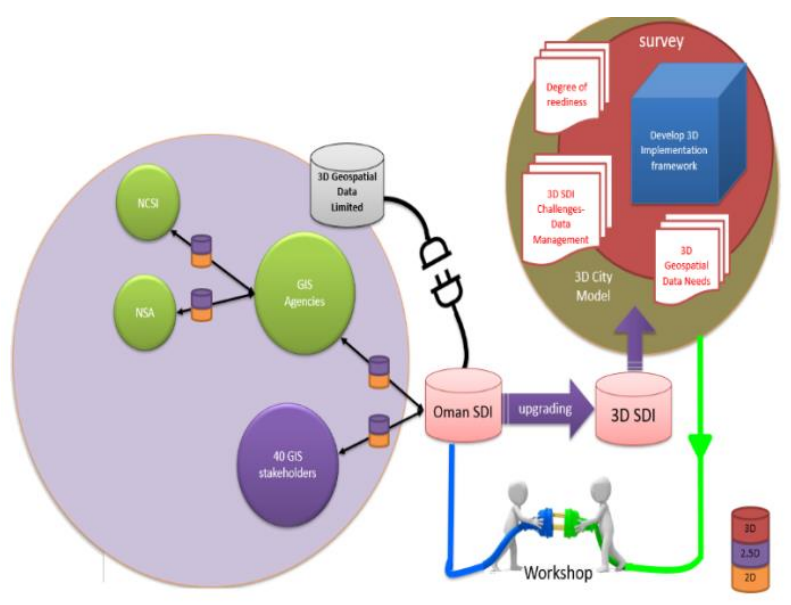

geospatial data (Figure 2).

Figure 2. Framework for implementing the 3D SDI in Oman

Moreover, it should be based on a clear understanding of the challenges and potential values of 3D SDI (Blomqvist, 2010; Xu et al., 2010; Kitsakis and Dimopoulou, 2016; Biljecki, 2017; Salim, 2017).

\subsection{Degree of readiness for 3D geo spatial data infrastructure in Oman}

The study will be based on a questionnaire which will be sent to all the service organizations within the government, private sector and other users in the country, Oman.
The purpose of the e-questionnaires is to determine the level of 3D geo-dataset implementation in Oman as well as find out the challenges that facing upgrading from 2D to 3D SDI to find out the challenges and data management issues. Moreover, one of the expected advantages of the study is that it will illustrate 3D prototype (Figure 3) for the Arabian infrastructure environment.

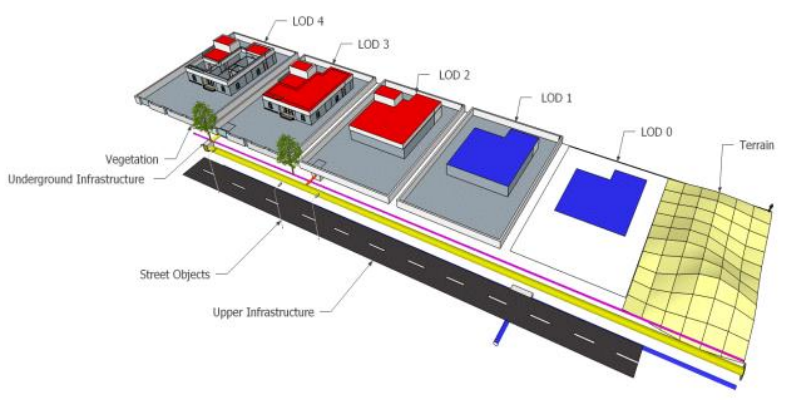

Figure 3. 3D Arabian infrastructure environment

\subsection{Key outline}

In order to implement and use the 3D geo-dataset and 3D SDI in Oman, the key outlines that can be addressed for the future implementation are:

- Upgrading the ONSDI structures from 2D to 3D.

- Monitor and coordinate the 3D implementation and management of the 3D roadmap, and develop an action plan across the government geospatial sectors.

- Associate with the national and international institution in terms of 3D implementation and research.

\section{CONCLUSION}

This paper attempts to review the current status of 2D and 3D Spatial Data Infrastructure (SDI) in Oman. However, the geospatial framework provides the key outline to achieve the master plan goals and assess the progress. In fact, some of the geospatial communities build their strategic in 2D geospatial for long periods. Then later, they face various challenges for upgrading it to 3D and 4D. In fact, strategic plans and missions should be flexible in order to accommodate new technology.

The initial study shows that further steps are needed for 3D SDI such as organize 3D geospatial workshop in Oman (to share the 3D geospatial knowledge and to identify the most important challenges in developing 3D SDI). In future studies, we will enhance and investigate further in order to address the requirement for the $3 \mathrm{D}$ SDI.

\section{REFERENCES}

Alsultan, S. H. and Rahman, A. A. (2015) Kingdom of Saudi Arabia Geospatial Information Infrastructure; An Initial Study' ISPRS - International Archives of the Photogrammetry, Remote Sensing and Spatial Information Sciences, XL-2/W4(October), pp. 95-99. doi: 10.5194/isprsarchives-XL-2-W4-95-2015.

Alwardi, A. (2015) Factor Impeding the Development of Oman Spatial Data Infrastructure (PhD's Thesis). Universiti 
The International Archives of the Photogrammetry, Remote Sensing and Spatial Information Sciences, Volume XLII-4/W9, 2018 International Conference on Geomatics and Geospatial Technology (GGT 2018), 3-5 September 2018, Kuala Lumpur, Malaysia

Teknologi Malaysia.

Biljecki, F. (2017) Level of details in 3D city models, Published PhD thesis,Delft University of Technology. doi: 10.4233/uuid:f12931b7-5113-47ef-bfd4-688aae3be248.

Blomqvist, D. (2010) 3D-visualizations for building interiors in a GIS perspective. institutionen for matematik,Sweden.

Das, A., Chandel, K. and Narain, A. (2017) Value of Geospatial Techology in Boosting Omans Economy, in Oman Geospatial Forum 2017. Muscat: Oman National Survey Authority, pp. 174.

ESRI (2017) $3 D$ feature. Available at: http://support.esri.com/en/other-resources/gisdictionary/term/3d feature (Accessed: 1 October 2017).

Ho, S., Rajabifard, A., Stoter, J. and Kalantari, M. (2013) Legal barriers to $3 \mathrm{D}$ cadastre implementation: What is the issue?, Land Use Policy, 35, pp. 379-387. doi: http://dx.doi.org/10.1016/j.landusepol.2013.06.010.

Kitsakis, D. and Dimopoulou, E. (2016) Possibilities of Integrating Puplic Law Restrictions to 3D Cadastres, 5th International Workshop on 3D Cadastres. Athens, Greece.

Kitsakis, D., Paasch, J., Paulsson, J., Navratil, G., Vucic, N., Karabin, M., Carneiro, A. and El-Mekawy, M. (2016) 3D Real Property Legal Concepts and Cadastre: A Comparative Study of Selected Countries to Propose a Way Forward (Overview Report), in 5th International Workshop on 3D Cadastres, pp. 124.

Li, D., Shan, J., Shao, Z., Zhou, X. and Yao, Y. (2013) Geomatics for Smart Cities - Concept, Key Techniques, and Applications, Geo-spatial Information Science. Taylor \& Francis, 16(1), pp. 13-24. doi: 10.1080/10095020.2013.772803.
Mao, W.-Q. (2014) Study on the Construction and Application of 3D Geographic Information Services for the Smart City, ISPRS Annals of Photogrammetry, Remote Sensing and Spatial Information Sciences, II-4, pp. 41-44. doi: 10.5194/isprsannalsII-4-41-2014.

NCSI (2017a) Oman National Spatial Data Infrastructure. Available https://www.ncsi.gov.om/Elibrary/LibraryContentDoc/ben_Om an National Spatial Data Infrastructure_1303dfbd-ce6d-4e13afee-62c137632eef.pdf.

NCSI (2017b) Oman National Spatial Data Infrastructure Strategy V5.0, (June). Available at: https://www.ncsi.gov.om/Elibrary/LibraryContentDoc/ben_Om an National Spatial Data Infrastructure_1303dfbd-ce6d-4e13afee-62c137632eef.pdf.

Roić, M. (2012) Upravljanje zemljišnim informacijama. Zagreb, Croatia: Katastar, University of Zagreb, Faculty of Geodesy.

Salim, M. J. (2017) 3D Spatial Information Intended for SDI : A Literature Review, Problem and Evaluation, Journal of Geographic Information System, pp. 535-545. doi: 10.4236/jgis.2017.95033.

Xu, W., Zhu, Q., Du, Z. and Zhang, Y. (2010) Design and implementation of 3D model database for general-purpose 3D GIS, Geo-spatial Information Science, 13(3), pp. 210-215. doi: 10.1007/s11806-010-0309-7.

\section{Revised August 2018}

